\title{
O trabalho colaborativo na escola: o uso da tecnologia assistiva
}

\section{Collaborative work in school: the use of assistive technology}

\section{Rosana Carla do Nascimento Givigi* Universidade Federal de Sergipe}

Raquel Souza Silva** Universidade Federal de Sergipe

\section{Juliana Nascimento de Alcântara***} Universidade Federal de Sergipe

Thais Alves de Souza**** Universidade Federal de Sergipe

Vera Lucia Oliveira Ralin***** Pontifícia Universidade Católica de São Paulo

Resumo Neste trabalho se discute o processo de escolarizaçáo dos sujeitos com deficiência a partir de açôes-intervençóes realizadas na escola, possibilitadas pelo trabalho colaborativo. Objetivou-se descrever as açóes respaldadas na Política da Educação Especial na Perspectiva Inclusiva e como estas impulsionaram o processo educacional dos sujeitos com deficiência. Dessa forma, sustentou-se metodologicamente na pesquisa-ação sob perspectiva crítico-colaborativa. Participaram da pesquisa cinco escolas da rede pública regular que possuíam matriculados sujeitos com deficiência. Como resultados, destaca-se o acesso a um currículo mais inclusivo mediante a adaptação de diversos recursos pedagógicos através da implementação da Tecnologia Assistiva. Dessa forma, mostrou-se a necessidade de reorientar as práticas vigentes e buscar novos subsídios que possibilitem delinear uma escola verdadeiramente inclusiva.

PALAVRAS-CHAVE: Trabalho colaborativo; Tecnologia assistiva; Educação inclusiva.

Abstract This research discusses the process of education of people with disabilities from actions and interventions in school by the collaborative work. This study aimed to describe backed actions in Special Education Policy on Inclusive Perspective and how those boosted the educational process of disabled individuals. On this way, was used the methodology of the research action under critical-collaborative perspective. Five public regular schools were participants on this research, and those had enrolled subjects with disabilities. Thus, it showed the need to redirect existing practices and seek new grants that enable design a truly inclusive school. The results highlight the access to more inclusive curriculum by adapting various teaching resources through the implementation of Assistive Technology.

KEYWORDS: Collaborative work; Assistive technology; Inclusive education. 


\section{Introdução}

Nas últimas décadas são perceptíveis os avanços das políticas favoráveis à educação inclusiva. Isso se acentuou na década de 1990, numa conjuntura na qual documentos como a Declaração Mundial sobre Educação para todos, deflagrada na Conferência Mundial de Educação para Todos ocorrida em Jomtien, Tailândia (1990), convoca o mundo a tecer um olhar de prioridades para a Educação, colocando-a no principal eixo das discussões ao almejar ações mais prospectivas (UNESCO, 1994).

Outro importante documento é a Declaração de Salamanca, que reafirma o direito de todas as pessoas à educação, em especial as pessoas com deficiência. A proposta é de uma escolarização para todos, independente das especificidades e da classe social dos sujeitos. Aponta que "devem acolher crianças com deficiência e bem dotadas, que vivem nas ruas e trabalham, de populações distantes, de minorias linguísticas, étnicas ou culturais [...]" (UNESCO, 1994, p. 3).

Aqui no Brasil houve, dentre outras, a Política Nacional de Educação Especial (1994); a Lei de Diretrizes e Bases da Educação Nacional (1996); o Plano Nacional da Educação (2001); o Plano de Desenvolvimento da Educação (2007); a Política Nacional de Educação Especial na Perspectiva da Educação Inclusiva (2008); o Decreto 186/2008 e 69489/2009, que garantem o direito à educação inclusiva em todos os níveis; o Decreto 7611/2011, que institui o FUNDEB e orienta a utilização de recursos; dentre outros.

$\mathrm{Na}$ busca pela ruptura das desigualdades no âmbito escolar, a Educação Inclusiva é tomada como uma ação política, social, pedagógica e cultural (BRASIL, 2007). Esta é descrita como um novo conceito em educação cuja característica principal é a defesa pelo diverso, pelo heterogêneo. Tal diversidade se constitui como extremamente relevante para a incitação de aprendizagens e, nesse sentido, procura-se uma metodologia que se expanda perante as diferenças do alunado (BEYER, 2006).

Embora se tenha muitas leis, decretos e políticas, localizam-se ainda nas escolas velhas práticas que perpetuam o insucesso. Pouco domínio teórico-metodológico do professor, falta de articulação entre gestores e professores e resistência em trabalhar com a diversidade são alguns dos problemas que engessam a organização de estratégias pedagógicas.

Com o aluno com deficiência as dificuldades ficam mais aparentes. Além de uma reorganização educacional, esses sujeitos poderão necessitar de recursos de Tecnologia Assistiva (TA). O Ministério da Educação Brasileiro, em 2007, descreveu a Tecnologia Assistiva no documento sobre o Atendimento Educacional Especializado (AEE), como:

[...] uma área do conhecimento, de característica interdisciplinar, que engloba produtos, recursos, metodologias, estratégias, práticas e serviços que objetivam promover a funcionalidade, relacionada à atividade e participação de pessoas com deficiência, incapacidades ou mobilidade reduzida, visando sua autonomia, independência, qualidade de vida e inclusão social. (BRASIL, 2007, ata da III reunião, linhas 225-230). 
Dentro da Tecnologia Assistiva encontra-se a Comunicação Alternativa e Ampliada. Esta é conceituada como uma área de atuação clínica e educacional que visa subsidiar a comunicação de sujeitos com comprometimentos severos na via da expressividade (GONÇALVES, 2008).

De acordo com a American Speech and Hearing Association - ASHA (1991, p. 9):

A CAA é uma área da prática clínica, de pesquisa e educacional para profissionais que visam compensar e facilitar, temporária ou permanentemente, padrões de prejuízo e inabilidade de indivíduos com severas desordens expressivas e/ou descobertas na compreensão de linguagem.

Nessas múltiplas linhas de ação, se faz necessária uma atuação conjunta e articulada dos profissionais que estão na escola para que se potencializem as práticas educativas. Nessa articulação das práticas, algumas questões seriam: o planejamento diário, a adaptação curricular, adaptação do material escolar e individual, adaptação dos recursos pedagógicos, bem como propostas de estratégias que abarquem a interação entre os pares e a comunicação em consonância às especificidades do alunado. Segundo Smith (2008) os professores precisam redirecionar sua metodologia, bem como realizar ajustes no currículo, de modo que sejam vistas as singularidades da pessoa com deficiência no processo de aprendizagem.

As práticas deveriam estar alicerçadas na Política da Educação Especial na Perspectiva da Educação Inclusiva (2008), que preconiza que os sistemas de ensino devem assegurar ao aluno com deficiência condições de acesso ao espaço, aos recursos pedagógicos e à comunicação. Tais condições devem respeitar as singularidades e especificidades dos sujeitos envolvidos e a acessibilidade precisa transpor os empecilhos arquitetônicos, de comunicação e de acesso ao conhecimento.

Dessa forma, corroboramos com Givigi (2013, p. 257) quando esta se compromete com "a ideia de uma escola que se constitua na/pela diversidade, que reinvente sua organização e seus modos de funcionar para que possa ser espaço de todos. A democratização do acesso aos saberes depende dessa reinvenção".

Neste texto, o objetivo é descrever ações-intervenções resultantes de um trabalho colaborativo respaldado nos recursos de Tecnologia Assistiva em escolas da rede regular. Também se deseja compreender como estas impulsionaram o processo de inclusão e de aprendizagem das pessoas com deficiência.

\section{Metodologia}

\section{Aporte teórico-metodológico}

Metodologicamente, baseia-se na pesquisa-ação de perspectiva crítico-colaborativa. Segundo Jesus (2008), a perspectiva crítico-colaborativa da pesquisa-ação procura ser um meio de mudança, propondo-se a ter um efeito discursivo na constante reflexão sobre a ação. Constrói-se uma nova concepção de pesquisador na medida em 
que este busca novos saberes e outras formas de conhecimento como meios de formação e mudança participativa. Nesse sentido, os participantes procuram reelaborar seus papeis e se configuram na práxis, ação teoricamente sustentada.

Jesus e Givigi (2011) apontam que sendo a pesquisa-ação política e participativa, esta exige do pesquisador um pensamento e uma ação coletiva, num processo que mobiliza e direciona ações, pretendendo uma reflexão crítica do trabalho desenvolvido. Nesse processo interativo, pesquisador e pesquisado unem-se em virtude da coletividade, se constituindo nesse movimento, afastando qualquer posição de autoridade e opressão. Dessa forma, escolher a pesquisa-ação crítico-colaborativa diz de uma concepção ético-política do pesquisador, o qual prioriza a modificação da realidade ao buscar a autonomia dos sujeitos.

\section{Seleção dos sujeitos}

Participaram dessa pesquisa 05 escolas da rede pública regular de ensino, localizadas no nordeste brasileiro, estado de Sergipe. Três dessas escolas situam-se no município de Aracaju, em bairros periféricos. As outras duas escolas localizam-se em um município circunvizinho na região da Grande Aracaju, também em bairros periféricos. Duas dessas escolas pertencem à rede estadual, outras duas pertencem à rede municipal e uma é particular. As escolas foram escolhidas mediante a matrícula de alunos com deficiência que eram atendidos no espaço Clínico Fonoaudiológico de Comunicação Alternativa da Universidade Federal de Sergipe.

$\mathrm{Na}$ seleção desses sujeitos tinha-se como critério de inclusão possuir de 07 a 13 anos de idade, diagnóstico de paralisia cerebral ou autismo, além de estarem inseridos na escola regular.

\section{Procedimentos}

Este trabalho é um recorte de uma pesquisa mais ampla do Grupo de Estudos em Linguagem e Comunicação (GELC). O referido grupo realiza um trabalho clínico e educacional com pessoas com deficiência através da implementação dos procedimentos técnicos/metodológicos da Comunicação Alternativa no trabalho com a linguagem (clínica) e com práticas inclusivas e educacionais com recursos de Tecnologia Assistiva.

A pesquisa aconteceu no período de março 2012 a dezembro de 2014. No total foram 240 visitas. O acompanhamento das escolas ocorreu mediante visitas semanais. Inicialmente, o objetivo era conhecer a instituição, traçar um diagnóstico institucional do local, estabelecer parcerias e conhecer a forma de trabalho.

Posteriormente, fazia-se a proposta de um trabalho de colaboração considerando as especificidades do alunado. As ações-intervenções foram alicerçadas nos princípios da Educação Inclusiva e subsidiadas pelos recursos de Tecnologia Assistiva, buscando contribuir para o processo de escolarização dos sujeitos com deficiência. 
Os dados apresentados neste trabalho são resultado de intervenções realizadas nas escolas. Os encontros foram registrados por escrito e documentados em relatórios semanais pelos pesquisadores.

\section{Resultados e discussão}

Repensar o processo de escolarização de pessoas com deficiência na escola é um ponto nodal da escola regular. O esclarecimento das políticas públicas, bem como o modo que a escola se organiza, não são suficientes para o fortalecimento de uma escola inclusiva. É preciso movimentar as práticas, reinventar as estratégias, pensar novos subsídios para que esses sujeitos tenham acesso ao currículo inclusivo.

Ao almejar mudanças prospectivas em favor do processo educacional dos sujeitos foi necessário um trabalho paulatino construído a cada visita, a cada diálogo, a cada tentativa de redirecionamento das práticas.

Nesta pesquisa as visitas ocorreram semanalmente, respeitando o funcionamento autônomo das escolas e os imprevistos inerentes do sistema público (greves, reformas), o que implicou no número de visitas realizadas (Quadro 1).

Quadro 1 - número de visitas ocorridas durante o ano letivo

\begin{tabular}{|l|l|l|}
\hline Ano & Escolas & Número de visitas ao ano \\
\hline 2012 & 05 escolas da rede regular & 93 visitas \\
\hline 2013 & 05 escolas da rede regular & 77 visitas \\
\hline 2014 & 05 escolas da rede regular & 70 visitas \\
\hline
\end{tabular}

Inicialmente, o planejamento de cada escola foi feito e era reavaliado permanentemente ao longo do trabalho, sempre baseado nas questões que emergiam nas visitas, no funcionamento da escola. Para fins didáticos, nesse texto, as análises serão divididas em dois momentos, a saber: observações e ações-intervenções, mesmo que na prática esses momentos fossem por vezes concomitantes. As ações-intervenções eram resultantes dessas observações e seguiam o ritmo da escola, bem como a intensidade dos problemas que se apresentavam. Nos quadros abaixo foram feitos agrupamentos do que se observou em relação ao trabalho de sala de aula e nos momentos livres, bem como as ações-intervenções desenvolvidas. 
Rosana Carla do Nascimento Givigi - Raquel Souza Silva - Juliana Nascimento de Alcântara

- Thais Alves de Souza - Vera Lucia Oliveira Ralin

Quadro 2 - Descrição de como se organizavam as ações na escola

OBSERVAÇÕES

\begin{tabular}{|c|c|c|}
\hline & Trabalho de sala de aula & Momentos Atividades Livres \\
\hline 2012 & $\begin{array}{l}\text { - Ausência de atividades } \\
\text { pedagógicas; } \\
\text { - Ausência de planejamento; } \\
\text { - Predomínio de atividades } \\
\text { motoras, uso da letra cursiva; } \\
\text { - Regalias justificadas pela } \\
\text { deficiência: privilégios na } \\
\text { hora do lanche, entrada, } \\
\text { permanência e saída da aula; } \\
\text { - Ausência de adaptação dos } \\
\text { conteúdos ou dos materiais } \\
\text { individuais. }\end{array}$ & $\begin{array}{l}\text { - Ausência de interação entre } \\
\text { os pares, tanto na sala de } \\
\text { aula quanto nas atividades } \\
\text { recreativas; } \\
\text { - Privação do recreio: } \\
\text { sentados na cantina ou } \\
\text { em espaço com pouco } \\
\text { movimento; } \\
\text { - Ausência de participação } \\
\text { nas atividades físicas; } \\
\text { - Falta de cooperação entre } \\
\text { os pares. }\end{array}$ \\
\hline 2013 & $\begin{array}{l}\text { - Diminuição das regalias } \\
\text { concedidas: maior } \\
\text { cumprimento das regras; } \\
\text { - Pouca sistematicidade na } \\
\text { aplicação das estratégias } \\
\text { pedagógicas; } \\
\text { - Predomínio de atividades } \\
\text { motoras; } \\
\text { - Assistematicidade no uso } \\
\text { dos recursos de Tecnologia } \\
\text { Assistiva. }\end{array}$ & $\begin{array}{l}\text { - Pouca interação entre } \\
\text { os pares, tanto na sala de } \\
\text { aula quanto nas atividades } \\
\text { recreativas; } \\
\text { - Recreio livre com pouca } \\
\text { supervisão; } \\
\text { - Presença nas atividades } \\
\text { físicas; } \\
\text { - Pouca cooperação entre os } \\
\text { pares; } \\
\text { - Manutenção de } \\
\text { comportamentos e } \\
\text { brincadeiras competitivas e } \\
\text { pouco inclusivas. }\end{array}$ \\
\hline
\end{tabular}




\begin{tabular}{|c|c|c|}
\hline 2014 & $\begin{array}{l}\text { - Aplicação de atividades } \\
\text { pedagógicas; } \\
\text { - Maior sistematicidade } \\
\text { no uso das estratégias } \\
\text { pedagógicas pensadas; } \\
\text { - Maior sistematicidade } \\
\text { no uso dos recursos de } \\
\text { Tecnologia As+A1:C5 } \\
\text { Asistiva.; } \\
\text { - Pouca correlação com o } \\
\text { professor da sala de AEE; } \\
\text { - Maior adesão as regras: } \\
\text { participação nas filas e } \\
\text { cumprimento de horários. }\end{array}$ & $\begin{array}{l}\text { - Maior interação entre } \\
\text { os pares, tanto na sala de } \\
\text { aula quanto nas atividades } \\
\text { recreativas; } \\
\text { - Recreio livre com maior } \\
\text { supervisão dos adultos; } \\
\text { - Maior sistematicidade nas } \\
\text { atividades físicas; } \\
\text { - Atividades recreativas } \\
\text { pensadas coletivamente; } \\
\text { - Maior cooperação entre os } \\
\text { pares: auxilio e relação na } \\
\text { sala de aula. }\end{array}$ \\
\hline
\end{tabular}

Quadro 3- Ações-intervenções realizadas nas escolas respaldadas no trabalho colaborativo e na perspectiva da Educação Inclusiva.

\begin{tabular}{|c|c|}
\hline \multicolumn{2}{|c|}{ AÇÃO-INTERVENÇÃO } \\
\hline \multicolumn{2}{|c|}{ TRABALHO COLABORATIVO } \\
\hline 2012 & $\begin{array}{l}\text { - Reunião com a gestão; } \\
\text { - Encontros individuais com os professores } \\
\text { da sala; } \\
\text { - Adaptação curricular, do material escolar } \\
\text { (atividades em sala, livros, cadernos), } \\
\text { adaptação do material individual; } \\
\text { - Sugestão do uso da letra bastão; } \\
\text { - Palestras sobre o uso dos recursos de } \\
\text { Tecnologia Assistiva com professores; } \\
\text { - Mediação da relação das crianças com } \\
\text { os pares em atividades recreativas e datas } \\
\text { comemorativas. }\end{array}$ \\
\hline
\end{tabular}




\begin{tabular}{|c|c|}
\hline 2013 & $\begin{array}{l}\text { - Reunião com a gestão; } \\
\text { - Reuniões individuais com os professores; } \\
\text { - Uso dos recursos de tecnologia assistiva: } \\
\text { letras móveis, dominós temáticos, ábaco de } \\
\text { madeira, jogos silábicos; } \\
\text { - Adaptação curricular; } \\
\text { - Palestra sobre os recursos de Comunicação } \\
\text { Alternativa e Ampliada para os professores; } \\
\text { - Execução de atividades lúdicas; } \\
\text { - Mediação nas atividades recreativas e nas } \\
\text { aulas de educação física; } \\
\text { - Colaboração nas atividades pedagógicas } \\
\text { diárias. }\end{array}$ \\
\hline 2014 & $\begin{array}{l}\text { - Reunião com a equipe pedagógica; } \\
\text { Adaptação curricular; } \\
\text { - Implementação dos recursos de } \\
\text { Comunicação Alternativa: pranchas móveis } \\
\text { com velcros, uso do sistema de CAA; } \\
\text { - Uso dos recursos de tecnologia assistiva: } \\
\text { contagem de histórias com material adaptado, } \\
\text { adaptação do sinal de adição e subtração, } \\
\text { letras móveis, dominós pedagógicos; } \\
\text { - Mediação das atividades recreativas e nas } \\
\text { aulas de educação física; } \\
\text { - Execução de atividades lúdicas; } \\
\text { - Colaboração nas atividades pedagógicas } \\
\text { diárias; } \\
\text { - Avaliações adaptadas com o uso de pranchas } \\
\text { e da TA. }\end{array}$ \\
\hline
\end{tabular}

Inicialmente sempre nos deparamos com escolas com concepções frágeis quanto à inclusão. $\mathrm{Na}$ maioria das escolas os alunos estavam matriculados, contudo, não participavam da dinâmica da aula, não lhes eram destinadas atividades pedagógicas, não se subjetivavam enquanto alunos.

Havia a ausência de um planejamento específico para as turmas, planejamento diário, adaptação do material. Os alunos com comprometimento motor estavam na sala de aula, todavia, não possuíam material pedagógico específico. A pedagogia estava alicerçada no tradicionalismo com o predomínio de atividades motoras: 
cobrir pontilhados, desenhos, pinturas, uso da letra cursiva. A ideia predominante era que inicialmente esses alunos deveriam adquirir a coordenação motora fina, ou seja, o treino motor seria um preditivo para se construir a leitura e a escrita; algo quase inacessível para pessoas com deficiência motora, o que os deixava à margem do processo educacional. $\mathrm{Na}$ constatação das falhas dessa metodologia, as possibilidades também se esgotam e a impossibilidade de acompanhar as aulas é sacramentada.

O próprio treino motor é datado da década de 20 e 30 e foi denominado de caligrafia muscular. Resultou de uma demanda social na qual era urgente uma escrita clara, legível e rápida. Foi uma forma de racionalizar a escrita, numa época em que era preciso otimizar as tarefas. Adveio de uma das transformações da Escola Nova, na qual a criança era solicitada a apurar o movimento dos braços e das mãos, a partir de exercícios com desenhos no ar e/ou no papel. Só posteriormente a esse controle corporal iniciava-se o trabalho com as letras (VIDAL, 2000).

Fica claro que por trás dessa metodologia havia um pensamento e uma pedagogia alicerçada nas demandas sociais da época. Hoje, nossa realidade e nossas urgências são outras. A inclusão está em pauta e a escola precisa de uma reorganização de papeis, bem como de uma metodologia que atenda ao alunado e que corrobore com suas especificidades e não contra elas. É urgente pensar: até quando esses sujeitos estarão à margem? Até quando as instituições de ensino se utilizarão de metodologias que os excluem?

Nessa discussão, Franco e Guerra (2015, p. 316) pontuam:

O que é questionável nesse processo é a tendência da escola em resolver os problemas da diversidade que se manifestam no âmbito escolar por meio de soluções práticas e pouco teóricas e reflexivas acerca do processo de inclusão e de participação efetiva da criança com deficiência. É comum a reprodução de discursos prontos e de senso comum, como, por exemplo: "essa criança tem problema de coordenação", "ele tem problema de cabeça”, como, também, discursos que justifiquem o não-aprender ou o não-fazer pedagógico adequado à situação e demanda da criança. Os docentes costumam se sentir à vontade para, a partir de conhecimentos superficiais, dizer que determinadas crianças não aprendem porque têm deficiências.

Essas práticas corroboram com a ideia de que esses sujeitos não respondem ao modelo de educação idealizado e são excluídos do processo educacional. Dessa forma, se reproduz na escola regular o que acontecia nas instituições especializadas: o fracasso justificado pela deficiência, pelo laudo médico (JESUS e AGUIAR, 2014).

Aos alunos com autismo eram concedidas regalias: poder se ausentar da sala de aula a qualquer hora ou não frequentá-las; utilizar o parque ou brinquedoteca no horário das aulas; adentrar em dependências da escola vetadas para os outros alunos.

$\mathrm{Na}$ sala de aula havia poucas propostas que propusessem a interação com os pares. Com uma proposta metodológica engessada, as atividades em sala de aula não contemplavam todo o alunado, sendo os alunos com deficiência excluídos desse processo. Mesmo após o trabalho colaborativo na implementação dos recursos de Tec- 
nologia Assistiva, uma proposta que contemplasse o coletivo era de difícil execução, visto que existia um conteúdo curricular que precisava ser avançado.

É visível que as escolas possuem dificuldades em instituir outros métodos/ recursos de aprendizagem, principalmente com alunos que não utilizam o padrão normal de escrita, de aprendizagem. Além disso, o currículo é trabalhado de forma rígida e baseado em uma ideia de linearidade. Nesse modelo não são considerados os sujeitos reflexivos, ativos, com diversos processos de subjetivação. Tudo isso alimenta a lógica da exclusão (TUNES e BATHOLO, 2008).

Nas atividades livres, os sujeitos ficavam sob os cuidados dos seus professores. Os alunos que tinham comprometimento motor eram vetados do recreio, lanchavam na sala da aula, longe do barulho e da movimentação das brincadeiras. Já os alunos autistas que tinham questões interacionais ficavam livres, mas sem participarem de nenhuma brincadeira, sem qualquer processo de mediação.

A deficiência não é algo focal, próprio somente do sujeito com deficiência, mas algo fomentado e sustentado nas relações sociais. Dessa forma, é necessário suscitar e mediar a interação desses sujeitos em variados espaços, como na escola, na família e nos demais grupos que os envolvam (GARGHETTI, NUERNBERG, MEDEIROS, 2015).

Com a atividade colaborativa buscou-se envolver esses sujeitos no contexto das brincadeiras e nas organizações simples da sala de aula, a exemplo de participar de filas e chamadas e se alimentar junto com os demais alunos. As atividades recreativas eram pensadas para que todos participassem, diminuindo as barreiras da deficiência.

As reuniões com a gestão eram realizadas no início do ano letivo. A proposta era uma reunião com toda a equipe, contudo, a dinâmica da escola dificultava um encontro com todos os envolvidos, ficando as ações fragmentadas. Dessa forma, o maior alvo das ações era o professor da sala de aula, pois estava à frente do processo educacional.

A introdução da adaptação curricular e do material possibilitou uma reorientação dos papeis estabelecidos. Enalteceram possibilidades de aprendizagem, evidenciou-se que aqueles alunos poderiam adentrar no universo da alfabetização. A introdução de recursos de Tecnologia Assistiva (tais como jogos silábicos, letras móveis, dominós temáticos, suporte/engrossador para lápis, tesoura, cola), bem como os de Comunicação Alternativa (pastas de comunicação, pranchas pictográficas temáticas, pranchas móveis) proporcionou a possibilidade de novas relações no processo de aprender desses alunos.

Com o trabalho colaborativo, esperava-se que o professor se empoderasse dessa ferramenta e se permitisse galgar novos caminhos no processo de ensino-aprendizagem dos seus alunos, rompendo com o velho modelo excludente. Um caminho lento, pois se lida com lógicas homogeneizadoras, que são alimentadas pelo sistema vigente na escola. Nesse sentido, percebe-se a dificuldade em sistematizar a aplicação de novas estratégias. Nos dias em que estávamos na escola essas novas atividades aconteciam em colaboração, mas as práticas pareciam não ter continuidade nos demais dias. 
Posta essa dificuldade em sistematizar estratégias e recursos que permitam o acesso dos sujeitos com deficiência ao currículo, Alcântara (2014, p. 144), aponta questões cruciais acerca da construção do currículo inclusivo:

\begin{abstract}
O currículo configura instrumento poderoso, capaz de reforçar ou desqualificar o processo inclusivo, tem cunho político-ideológico, dimensiona a constituição de um determinado tipo de sujeito e da pluralidade de posicionamentos nas divisões sociais. Por muito tempo, vozes foram autorizadas e outras silenciadas e as culturas hegemônicas perpassaram as propostas curriculares das escolas por incontáveis gerações. Pela lógica capitalista, de interesses mercadológicos e produtivistas, com o esvaziamento da subjetividade, conceber um currículo inclusivo parece incompatível com as premissas que a regem, posto que o currículo inclusivo deve primar pela valorização da diferença.
\end{abstract}

Numa necessidade de articular teoria e prática, de modo que as ações movimentassem melhor a escola, surgiram as palestras. Estas vieram para respaldar teoricamente as ações e fomentar a discussão para novas possibilidades de estratégias e recursos, de como esse currículo poderia tornar-se acessível para os sujeitos com deficiência. Era aberta para toda a escola e realizada num momento fornecido por eles. Havia um conhecimento incipiente quanto aos tipos e possibilidades do uso correto dos recursos e na articulação de ambos para pensar as formas de adaptação, até mesmo por parte do professor especializado (do Atendimento Educacional Especializado - AEE).

Num primeiro ano manteve-se o foco nas Tecnologias Assistivas de forma mais ampla, de modo que possibilitasse à escola repensar as estratégias pedagógicas lançadas para os sujeitos. E, num segundo momento, o foco das Tecnologias Assistivas foi voltado para a Comunicação Alternativa, no sentido de otimizar a relação e comunicação entre os sujeitos e a escola. Apesar de ter focos distintos nas palestras, as ações, discursos e práticas ao longo dos anos coadunavam ambos os recursos técnicos/ metodológicos.

A ida mais sistemática às salas de AEE ocorreu em 2014, mediante a organização das escolas e os acordos realizados com as famílias. Ainda assim, apesar de a priori ser um professor mais instrumentalizado, as práticas centradas na visão médico-positivista eram perpetuadas, o que afastava o aluno de acompanhar o currículo.

Outra característica era que inicialmente precisava-se reestabelecer uma função motora para o aluno com deficiência conseguir ser inserido no processo de ensino, ou ainda eram evidenciadas suas limitações físicas em detrimento da ausência de um material que atendesse as suas necessidades, posições que impediam avanços no âmbito educacional. As salas possuem os recursos, mas é comum discursos que justifiquem o não aprender pelos aspectos cognitivos dos sujeitos, bem como não saber utilizá-los por não ter recebido instrução para tal, principalmente os de alta tecnologia.

É importante destacar que o AEE é um serviço da educação especial com notória expansão, impulsionado pela política de Educação Inclusiva e possibilitado pelo Programa de Implantação das Salas de Recursos Multifuncionais. Através deste programa são implementadas nas redes públicas de ensino salas equipadas com ma- 
teriais pedagógicos, didáticos e de acessibilidade respaldados na Tecnologia Assistiva (TA), além de mobiliário adaptado possibilitando, assim, um espaço de excelência, com estrutura adequada para que ocorra o AEE (BRIDI, 2012).

Nesse sentido, perpetuando essa visão clínico-terapêutica, muitos trabalhos visam o treinamento de aspectos cognitivos sem que haja um planejamento que subsidie o processo educacional desses sujeitos, corroborando com ações estanques que não dialogam com o processo inclusivo que ocorre na escola. Muitas vezes há o uso dos recursos, mas esses são dissociados do trabalho que acontece em sala de aula, promovendo ações fragmentadas e sem resultados mais efetivos, que não se materializam em grandes avanços no âmbito da aprendizagem (ALCÂNTARA, 2014).

Numa concretização maior dos recursos, em 2014, foram feitas as avaliações adaptadas. Encarando a avaliação como aferição de um desempenho, mensuração de resultados, quantificação de conhecimento, tornou-se difícil para a escola conceber um processo avaliativo com o uso dos recursos, pois estes eram tomados como facilitadores desse ideal avaliativo. Essa concepção vai à contramão do processo de inclusão escolar em pauta nos últimos tempos, restringindo e deixando ainda mais à margem as pessoas com deficiência. Historicamente tomada como instrumento de seleção, esse caráter avaliativo está presente em diversos âmbitos do ser escola e do ser aluno e, dessa forma, se o sujeito com deficiência é retirado também desse momento, reafirma-se como está à deriva do processo educacional.

Uma avaliação pautada em verificação de conteúdo pouco contribui para o professor compreender o processo de relação do aluno com o conhecimento, como também não o auxilia a repensar estratégias pedagógicas que modifiquem e potencializem essa relação. Essa forma de conceber a avaliação vai de encontro a uma proposta de educação para todos, de uma escola inclusiva, pois não se enaltecem as singularidades dos alunos, nos diferentes modos de ser e aprender (CRISTOFARI, 2012).

Dessa forma, a ressignificação do lugar que o sujeito com deficiência ocupa na escola e as possibilidades de aprendizagem evidenciadas com o uso dos recursos potencializaram outros modos de pensar a educação e proveram modificações que culminaram nas avaliações adaptadas. Givigi et al. (2015) discute como as Tecnologias Assistivas se presentificam como instrumentos que medeiam o processo de escolarização dos sujeitos. Os autores enaltecem também que a escola precisa valer-se de novas ferramentas avaliativas, como recursos pedagógicos adaptados, computadores, pranchas de comunicação, hardwares e softwares voltados para a aprendizagem, atinentes à inclusão.

Nesse viés, o trabalho colaborativo movimentou as escolas para um novo eixo de ação frente aos alunos com deficiência. Possibilitando uma recolocação do lugar que este aluno ocupa na escola, o rompimento com o dogma da homogeneidade, puderam ser efetivadas novas relações entre professor, escola e aluno, como também acesso ao conteúdo e novas possibilidades de construção da leitura e da escrita. 


\section{Conclusão}

$\mathrm{Na}$ atual perspectiva inclusiva é necessário e urgente pensar a escola diversa, pensar a escola para todos. Ao conceber os processos de subjetivação que envolvem esses sujeitos e valorizá-los como propulsores no ensino-aprendizagem exige-se a demarcação de novas formas de conceber o delineamento educacional vigente. Uma das mudanças necessárias seria a implementação dos recursos de Tecnologia Assistiva que são muitas vezes a única via de acesso desses alunos ao currículo.

Propiciar esse acesso pela via da adaptação curricular é o caminho na valoração das singularidades dos alunos, dessa forma, uma prática indispensável quando se pensa o processo educacional dos alunos com deficiência. Assim, é necessário o aprimoramento dos sistemas de ensino para que haja a garantia da implementação das políticas públicas e, por conseguinte, o fortalecimento da Escola Inclusiva, garantindo o direito à educação para todos.

Apontamos o trabalho colaborativo como uma possibilidade para que as políticas propostas possam se efetivar. Acreditamos que nele possa haver a abertura de vontades, de projetos coletivos e individuais, como disse Meirieu:

É, enfim, por este motivo, que é preciso que as instituições nos empurrem para fora de nós mesmos, nos obriguem a reerguer a cabeça, a olhar para mais longe do que os nossos interesses imediatos: para não estarmos fechados no nosso egocentrismo sem, por essa razão, renunciarmos o nosso ego. Visto que é precisamente esse o projecto de todas as instituições: permitir aos sujeitos que existam no mundo, que encontrem um lugar sem tomarem conta dos lugares todos, que vivam em conjunto de outra maneira que não a selvajaria das paixões que se confrontam. (2006, p. 24).

Ser colaborativo ultrapassa um valor ético para epistemologicamente indicar uma ação política. $\mathrm{Na}$ escola buscou-se o engajamento de todos para a construção das relações. Marcado pelas singularidades foi se construindo o coletivo, acolhendo a diversidade, convivendo com a diferença, com os conflitos, mas especialmente aprendendo a trabalhar junto.

\section{Referências}

ALCÂNTARA, J. N. A formação continuada de professores na perspectiva da educação inclusiva: desvelando os fios da trama. 2014. 230f. Dissertação (Mestrado em Educação) - Programa de pós-graduação em Educação, Universidade Federal de Sergipe, Aracaju. 2014.

AMERICAN Speech-Language-Hearing Association - Asha, Oxfordshire, 1991. Disponível em: <http://www.asha.org>. Acesso em: 12 maio 2013.

BRASIL. Ministério da Educação. Secretaria de Educação Especial. Política Nacional de Educação Especial. Brasília: MEC/SEESP, 1994.

. Ministério da Educação. Lei de Diretrizes e Bases da Educação Nacional. LDB 9.394, de 20 de dezembro de 1996.

. Ministério da Educação. Lei no 10.172, de 09 de janeiro de 2001. Aprova o Plano Nacional de Educação e dá outras providências. 
Rosana Carla do Nascimento Givigi - Raquel Souza Silva - Juliana Nascimento de Alcântara - Thais Alves de Souza - Vera Lucia Oliveira Ralin

BRASIL. 2007. Atendimento Educacional Especializado: deficiência física. Brasília: Ministério da Educação. Disponível em: http://portal.mec.gov.br/seesp/arquivos/pdf/aee_df.pdf. Acesso em: 10 jan. 2012.

Ministério da Educação. Conselho Nacional de Educação. Formação continuada a distância de professores para o atendimento educacional especializado. Brasília. 2007.

. Ministério da Educação. Plano de Desenvolvimento da Educação: razões, princípios e programas. Brasília: MEC, 2007.

. Ministério da Educação. Secretaria de Educação Especial (SEESP). Política Nacional de Educação Especial na Perspectiva da Educação Inclusiva. Brasília, 2008.

BEYER, H. O. Da integração escolar à educação inclusiva: implicações pedagógicas. In: BAPTISTA, C. R; BEYER, H. O (Orgs.). Inclusão e escolarização: mutiplas perspectivas. Porto Alegre: Mediação, 2006.p. 73-81.

BRIDI, F. R. S. A formação continuada em educação especial para o atendimento educacional especializado. In: $X V I E N D I P E$ - Encontro Nacional e Didática e Práticas de Ensino - UNICAMP - Campinas - 2012 .

CHRISTOFARI, A. C. Avaliação da aprendizagem e inclusão escolar: relações possíveis. In: Associação Nacional de Pós-Graduação e Pesquisa em Educação - ANPED SUL, 9, 2012. IX ANPED SUL, Caixias do Sul, 2012.p. 01-15. Site

FRANCO, M. A. M. GUERRA, L. B. O ensino e a aprendizagem da criança com paralisia cerebral: ações pedagógicas possíveis no processo de alfabetização. Revista Educação Especial. Santa Maria, v. 8, n. 52, p. 311-324, maio/ago., 2015. Disponível em: <http://cascavel.ufsm.br/ revistas/ojs-2.2.2/index.php/educacaoespecial/article/view/14916/pdf>. Acesso em: 08 jul 2015.

GARGHETTI, F. C.; NUERNBERG, A. H.; MEDEIROS, J. G. Um estudo observacional sobre as interações de crianças/adolescentes com deficiência intelectual no ensino regular. Educação. Santa Maria, v. 40, n. 2, p. 451-464, maio-ago., 2015. Disponível em: <http://cascavel. ufsm.br/revistas/ojs-2.2.2/index.php/reveducacao/article/view/15934/pdf>. Acesso em: 08 jul 2015.

GIVIGI, R. C. N. Costurando os fios de uma rede com o trabalho colaborativo. Discursos que contagiam. In: JESUS, D. M; SÁ, M. G. C. S. (Orgs). Políticas, Práticas Pedagógicas e Formação: Dispositivos para escolarização de alunos (as) com deficiência. Vitória: Edufes, 2013. p.257-274.

GIVIGI, R. C. N., ALCANTARA, J. N., SILVA, R. S., DOURADO, S. S. F. A avaliação da aprendizagem e o uso dos recursos de tecnologia assistiva em alunos com deficiências. Educação: Teoria e Prática. Rio Claro, v. 25, n. 48, p. 150-167, abr. 2015. Disponível em: <http://www. periodicos.rc.biblioteca.unesp.br/index.php/educacao/article/view/9199/6658>. Acesso em: 08 Jul. 2015

GONÇALVES, M. J. Comunicação Alternativa em Fonoaudiologia: uma área em expansão. Revista Cefac. São Paulo, v. 10, n. 3, jul./set., 2008. Disponível em: <http://www.scielo.br/scielo. php?script=sci_arttext\&pid=S1516-18462008000300002>. Acesso em: 08 jul. 2015.

JESUS, D. M. Dialogando com os contextos da realidade pela via da pesquisa-ação: instituindo práticas educacionais inclusivas. In: Encontro Nacional de Didática e Práticas de - ENDIPE, 14, 2008, Porto Alegre. Anais... Porto Alegre: Edipucrs, 2008. p. 215-225. (Vol. 3). Site.

JESUS, D. M.; AGUIAR, A. M. B. O calcanhar de Aquiles: do mito grego ao desafio cotidiano da avaliação inicial nas salas de recursos multifuncionais. Revista Educação Especial. Santa Maria, v. 25, n. 44, p.399-416, set-dez, 2012. Disponível em: http://cascavel.ufsm.br/revistas/ ojs-2.2.2/index.php/educacaoespecial/article/view/6532/pdf_1. Acessado em: 08 jul. 2015. 
JESUS, D. M. ; GIVIGI, R. C. N. Implicações Éticas na Pesquisa-Ação. In: LOPES, K. J. M; CARVALHO, E. N. C.; MATOS, K. S. A. L. (Orgs). Ética e as reverberações do fazer. Fortaleza: Edições UFC, 2011. p. 33-45.

MEIRIEU, P. O mundo não é um brinquedo. Tradução de Aline Rodrigues. Porto: Edições ASA, 2006.

SMITH, D. D. Introdução à educação especial: ensinar em tempos de inclusão. 5. ed. Porto Alegre: Artmed, 2008, p. 480.

TUNES, E.; BARTHOLO, R. O trabalho pedagógico na escola. In: TACCA, M. C. V. R. Aprendizagem e trabalho pedagógico. 2. ed., Campinas: Alínea, 2008.

UNESCO. Declaração de Salamanca. Sobre princípios, política e práticas na área das necessidades educativas especiais, Salamanca, 1994. Disponível em: <http://portal.mec.gov.br/seesp/ arquivos/pdf/salamanca.pdf $>$. Acesso em: set. 2014.

UNESCO. Declaração mundial sobre educação para Todos: satisfação das necessidades básicas de aprendizagem. Jomtien, 1990, 8p. Disponível em : http://unesdoc.unesco.org/images/0008/000862/086291por.pdf Acesso em: set. 2014.

VIDAL, D. G. Escola Nova e Processo Educativo. In: LOPES, E. M. T.; FARIA F., L. M. e VEIGA, C. G. 500 anos de educação no Brasil. Belo Horizonte, Autêntica, 2000. p. 497-517.

* Professora doutora da Universidade Federal de Sergipe, Aracaju, Sergipe, Brasil.

** Mestranda em Educação pela Universidade Federal de Sergipe, Aracaju, Sergipe, Brasil.

**** Doutoranda em Educação pela Universidade Federal de Sergipe, Aracaju, Sergipe, Brasil.

**** Graduada em Fonoaudiologia pela Universidade Federal de Sergipe, Aracaju, Sergipe, Brasil.

******** Mestre em Fonoaudiologia pela Pontifícia Universidade Católica de São Paulo, São Paulo, São Paulo, Brasil.

\section{Correspondência}

Rosana Carla do Nascimento Givigi - Universidade Federal de Sergipe, Centro de Ciências Biológicas e da Saúde. Cidade Universitária, Av. Marechal Rondon, Rosa Elze, 49000000 - Aracaju, Sergipe - Brasil. E-mail: rosanagivigi@uol.com.br - fgaraquelsouza@gmail.com - fgajulianalcantara@gmail.com - thaisalves.fono@gmail.com - verinharalin@gmail.com

Recebido em 11 de setembro de 2015

Aprovado em 10 de março de 2016 